\title{
Adubações orgânicas e mineral e controle biológico sobre a incidência de podridões de colmo e produtividade de milho
}

\section{Organics and mineral fertilizers and biological control on the incidence of stalk rot and corn yield}

\author{
Miria Rosa Durigon ${ }^{1 *}$; Elena Blume ${ }^{2}$; Marlove Fátima Brião Muniz²; \\ Paola Mendes Milanesi ${ }^{3}$; Ricardo Feliciano dos Santos ${ }^{4}$; \\ Leise Inês Heckler ${ }^{4}$; Jackson Berticelli Cerini ${ }^{5}$
}

\section{Resumo}

\begin{abstract}
A expansão da área cultivada com milho (Zea mays L.) e a utilização do plantio direto têm favorecido a incidência de podridões de colmo nessa cultura. $\mathrm{O}$ trabalho objetivou avaliar a adubação orgânica e mineral e o tratamento de sementes com Trichoderma spp. sobre a produção de matéria seca (MS) de parte aérea, incidência de podridões de colmo e produtividade de milho. $\mathrm{O}$ experimento constituiuse em um fatorial com parcelas subdivididas em faixas, no delineamento blocos casualizados com quatro repetições, sendo os tratamentos de adubação (dejeto líquido de suínos; cama sobreposta de suínos; dejeto líquido de bovinos; adubação mineral e tratamento testemunha) aplicados nas parcelas e o tratamento de sementes (com e sem Trichoderma spp.) nas subparcelas. No estádio de florescimento foram coletadas três plantas de milho por subparcela para a avaliação da produção de MS da parte aérea. No estádio de maturação fisiológica, foi realizada a avaliação da incidência de podridões de colmo e a colheita das espigas para a avaliação da produtividade. Os adubos orgânicos e o mineral aumentaram a produção de MS e a produtividade de milho. Trichoderma spp. aumentou a produção de MS de milho, porém não teve reflexo sobre a produtividade. A incidência de podridões de colmo no milho foi maior nos tratamentos com adubação orgânica e mineral. Adubos orgânicos aumentam a produção de matéria seca de parte aérea e a produtividade de milho e Trichoderma spp. proporciona aumento na produção de matéria seca de parte aérea de milho.
\end{abstract}

Palavras-chave: Zea mays L., dejetos, Trichoderma spp., produtividade, matéria seca, patógenos de solo

\begin{abstract}
The expansion of area under maize (Zea mays L.) and the use of no tillage have favored the incidence of stalk rot on this crop. The study aimed to evaluate the organic fertilizers and the treatment of corn seeds with Trichoderma spp. on the production of dry matter (DM) of shoot, incidence of stalk rot and corn yield. The experiment consisted in a factorial with split-plot in strips, on the randomized block design with four replicates, and the fertilization treatments (pig slurry; swine deep bedding; cattle slurry;
\end{abstract}

${ }^{1}$ Eng $^{\mathrm{a}} \mathrm{Agr}^{\mathrm{a}}$, Discente do Curso de Doutorado em Agronomia, Faculdade de Agronomia e Medicina Veterinária, FAMV, Universidade de Passo Fundo, UPF, Passo Fundo, RS. E-mail: midurigon@yahoo.com.br

${ }^{2}$ Prof $^{\text {as }}$ Associadas de Fitopatologia, Dept ${ }^{\circ}$ de Defesa Fitossanitária, Universidade Federal de Santa Maria, UFSM, Centro de Ciências Rurais, CCR, Santa Maria, RS. E-mail: elenablu@gmail.com; marlovemuniz@yahoo.com.br

${ }^{3}$ Eng $^{\text {a }}$ Agr $^{\text {a }}$, Pós-Doutoranda em Ciência do Solo, Dept ${ }^{\circ}$ de Solos, UFSM/CCR, Santa Maria, RS. E-mail: paola.milanesi@gmail. com

${ }^{4}$ Eng $^{\text {os }}$ Agr $^{{ }^{\text {s }}}$, Discentes do Curso de Mestrado em Agronomia, Dept ${ }^{\circ}$ de Defesa Fitossanitária, UFSM/CCR, Santa Maria, RS. E-mail: ricardoijui@hotmail.com; leiseins@yahoo.com.br

${ }^{5}$ Eng $^{\circ}$ Agr $^{\circ}$, M.e em Ciência do Solo, Dept ${ }^{\circ}$ de Solos, UFSM/CCR, Santa Maria, RS. E-mail: jabcerini@yahoo.com.br

* Autor para correspondência 
mineral fertilizer; control treatment) were applied to the plots and the seeds treatment (with and without Trichoderma spp.) in the subplots. At the flowering stage, three corn plants per subplot were collected for the assessment of DM production. At physiological maturity stage, the incidence of stalk rot was assessed, and the ears of corn harvested for productivity assessment. The organic and mineral fertilizers increased the production of DM and productivity of corn. Trichoderma spp. increased the production of DM of corn, but had no reflection on productivity. The incidence of stalk rot in corn was higher in treatments with organic and mineral fertilization. Organic fertilizers increase dry matter production of shoot and corn yield, and Trichoderma spp. provides an increase in dry matter production of shoot.

Key words: Zea mays L., wastes, Trichoderma spp., productivity, dry matter, soilborne pathogens

O milho (Zea mays) é um cereal amplamente cultivado no Brasil e no mundo. Na safra 2011/12, a produção brasileira de milho foi de 72,98 milhões de toneladas, com uma produtividade média de $4808 \mathrm{~kg} \mathrm{ha}^{-1}$, ainda considerada baixa em relação ao potencial da cultura (CONAB, 2010). Essa baixa produtividade média se deve, entre outros fatores, à ocorrência de doenças, que comprometem a produção, a qualidade e o valor nutritivo da forragem. Dentre tais doenças, estão as podridões de colmo, que podem levar a um menor tamanho e peso de grãos, morte prematura e tombamento de plantas. Fusarium graminearum Schwabe, F. proliferatum Sheld., Colletotrichum graminicola (Ces.) Wilson, Stenocarpella maydis (Berk.) Sutton. (Sin. Diplodia maydis (Berk.) Sacc.; D. zeae (Schw.) Lev.) e $S$. macrospora (Earle) Sutton (Sin. D. macrospora Earle in Bull.) estão entre os fungos causadores de podridões de colmo no milho, doenças essas caracterizadas pela alteração na coloração externa do colmo e parte interna dos nós e desintegração da medula (CASELA; FERREIRA; PINTO, 2006).

Os patógenos causadores de podridões de colmo na cultura do milho dificilmente são controlados por produtos químicos, devido às limitações na aplicação que impedem que o produto atinja essa parte da planta (PINTO; OLIVEIRA; FERNANDES, 2007). Aliado a isso, os impactos negativos causados pelos produtos químicos ao meio ambiente favorecem a procura por métodos alternativos no seu controle, como o controle biológico. Um dos organismos mais utilizados em controle biológico é o fungo Trichoderma spp. Persson, devido à sua alta capacidade reprodutiva e habilidade de sobreviver sob diversas condições desfavoráveis, que exerce sua ação sobre os fitopatógenos através da competição por nutrientes, antibiose e micoparasitismo e sobre as plantas pela indução de resistência e promoção do crescimento (BENÍTEZ et al., 2004).

Para que o antagonista possa ter condições de sobreviver no solo por um longo período de tempo após sua aplicação, esse deve ter um substrato favorável ao seu desenvolvimento, a fim de melhorar sua eficiência de controle (EL-HASSAN; GOWEN, 2006). A utilização de compostos orgânicos tornase uma ferramenta importante, pois serve como nutrição às plantas promovendo seu crescimento, contribui para a expressão do potencial antifitopatogênico dos solos e sua degradação pode resultar na liberação de compostos tóxicos a alguns fitopatógenos (SULLIVAN, 2004; GHORBANI et al., 2008).

A quantidade e forma disponível dos nutrientes fornecidos devem ser levadas em consideração no momento da escolha do adubo a ser aplicado na área, pois o excesso/escassez de determinados nutrientes pode aumentar/reduzir a incidência de doenças nas culturas. Para nitrogênio, a forma disponível no adubo pode afetar a severidade da doença devido a condição de pH criada no solo (GHORBANI et al., 2008). A absorção de $\mathrm{N}$ amoniacal por gramíneas torna a zona radicular mais ácida e leva a uma melhor absorção de manganês, reduzindo, em geral, a incidência de podridões de colmo na cultura do milho, enquanto que potássio, em quantidades adequadas, pode induzir resistência sistêmica e aumentar a quantidade de compostos fenólicos em algumas plantas (SULLIVAN, 2004).

O objetivo do presente trabalho foi avaliar a adubação orgânica e mineral e o tratamento de sementes com Trichoderma spp. sobre a produção 
de matéria seca de parte aérea, a incidência de podridões de colmo e a produtividade de milho.

O experimento foi realizado na área experimental do Departamento de Solos da Universidade Federal de Santa Maria, Santa Maria, na Depressão Central do Estado do Rio Grande do Sul, localizada a uma latitude de $29^{\circ} 45^{\prime} \mathrm{S}$, longitude de $53^{\circ} 42^{\prime} \mathrm{W}$ e altitude de $95 \mathrm{~m}$, na safra 2010/11. A área tem um histórico de aplicação de adubos orgânicos e mineral desde o ano de 2004.

O experimento constituiu-se de um fatorial com parcelas subdivididas em faixas, no delineamento blocos casualizados, com quatro repetições, sendo os adubos orgânicos e o mineral (dejeto líquido de suínos - DLS; cama sobreposta de suínos - CSS; dejeto líquido de bovinos - DLB; fertilizante mineral - NPK; tratamento testemunha (sem aplicação de adubos) aplicados na parcela principal, uma única vez durante o experimento, e o tratamento das sementes (com e sem Trichoderma spp.) nas subparcelas.

Amostras de solo foram coletadas, antes da semeadura do milho e da aplicação dos adubos orgânicos e mineral para seu cultivo, a $10 \mathrm{~cm}$ de profundidade, e encaminhadas ao Laboratório de Análises de Solo da Universidade Federal de Santa Maria (UFSM) para determinação da composição química. As diferenças encontradas na análise de solo entre os tratamentos deve-se ao fato de que a área experimental possuía um histórico de aplicação dos adubos orgânicos e o mineral desde o ano de 2004. Também foi determinada a composição química e o teor de matéria seca dos dejetos, conforme metodologias descritas em literatura (ALMEIDA, 2000; TEDESCO; GIANELLO; BISSANI, 1995). Ambos os resultados podem ser visualizados na tabela 1 .

Tabela 1. Características químicas do solo no início do experimento (outubro/2010) e composição química e teor de matéria seca $\left(\mathrm{g} \mathrm{kg}^{-1}\right)$ dos dejetos líquidos de suínos e de bovinos e da cama sobreposta de suínos e quantidades adicionadas $\left(\mathrm{kg} \mathrm{ha}^{-1}\right)$ nas parcelas. Santa Maria, RS. 2010.

Características químicas do solo no início do experimento

\begin{tabular}{|c|c|c|c|c|c|c|c|c|c|c|c|}
\hline \multirow{3}{*}{$\begin{array}{l}\text { Tratamento } \\
\text { TEST }^{2}\end{array}$} & \multirow{3}{*}{$\frac{\mathrm{pH} \mathrm{H_{2 }}}{5,3}$} & \multirow{3}{*}{$\begin{array}{c}\text { índice } \\
\text { SMP }\end{array}$} & \multicolumn{2}{|c|}{$\mathrm{P}$} & \multicolumn{2}{|c|}{$\mathrm{K}$} & \multicolumn{2}{|c|}{$\mathrm{CTC}_{\mathrm{pH} 70}$} & \multicolumn{2}{|c|}{$\mathrm{Al}^{3+}$} & \multirow{2}{*}{$\frac{\mathrm{MO}^{1}}{\%}$} \\
\hline & & & \multicolumn{4}{|c|}{$\mathrm{mg} \mathrm{dm}^{-3}$} & \multicolumn{4}{|c|}{$\mathrm{cmol}_{\mathrm{c}} \mathrm{dm}^{-3}$} & \\
\hline & & & \multicolumn{2}{|c|}{14,4} & \multicolumn{2}{|c|}{48,0} & \multicolumn{2}{|c|}{6,3} & \multicolumn{2}{|c|}{0,3} & 1,5 \\
\hline $\mathrm{DLS}^{3}$ & 5,4 & 6,3 & \multicolumn{2}{|c|}{72,0} & \multicolumn{2}{|c|}{64,0} & \multicolumn{2}{|c|}{7,0} & \multicolumn{2}{|c|}{0,2} & 1,8 \\
\hline $\mathrm{CSS}^{4}$ & 5,6 & 6,5 & \multicolumn{2}{|c|}{76,0} & \multicolumn{2}{|c|}{88,0} & \multicolumn{2}{|c|}{7,6} & \multicolumn{2}{|c|}{0,0} & 2,1 \\
\hline DLB $^{5}$ & 5,5 & 6,2 & \multicolumn{2}{|c|}{43,3} & \multicolumn{2}{|c|}{68,0} & \multicolumn{2}{|c|}{7,7} & \multicolumn{2}{|c|}{0,0} & 1,7 \\
\hline $\mathrm{NPK}^{6}$ & 5,3 & 6,1 & \multicolumn{2}{|c|}{24,8} & \multicolumn{2}{|c|}{52,0} & \multicolumn{2}{|c|}{7,1} & \multicolumn{2}{|c|}{0,4} & 1,6 \\
\hline \multicolumn{12}{|c|}{ Composição química e teor de matéria seca dos dejetos e quantidades adicionadas nas parcelas } \\
\hline \multirow{2}{*}{ Material } & \multirow{2}{*}{$\mathrm{MS}^{7}$} & \multirow{2}{*}{$\mathrm{C}$} & $\mathrm{N}-\mathrm{n}$ & eral & & & & & & & \\
\hline & & & $\mathrm{N}-\mathrm{NH}_{4}^{+}$ & $\mathrm{N}-\mathrm{NO}_{3}^{-}$ & $\mathrm{N}$-total & $\mathrm{P}$ & K & $\mathrm{Ca}$ & $\mathrm{Mg}$ & $\mathrm{C} / \mathrm{N}$ & $\mathrm{pH}$ \\
\hline & & & & & & & & & & & \\
\hline DLS & 9 & 0,7 & 0,03 & 0,28 & 2,48 & 0,98 & 3,71 & 0,7 & 0,3 & 0,3 & 7,8 \\
\hline CSS & 563 & 274,0 & 0,52 & 0,05 & 8,32 & 3,94 & 14,71 & 10,8 & 4,2 & 33,2 & 7,8 \\
\hline DLB & 60 & 1,0 & 0,57 & 0,14 & 1,79 & 0,42 & 4,40 & 0,8 & 0,3 & 0,5 & 7,3 \\
\hline & & & & & & & & & & & \\
\hline DLS & 476 & 37,0 & 1,6 & 14,8 & 105,0 & 46,7 & 196,3 & 37,0 & 15,9 & - & - \\
\hline CSS & 14210 & 6915,8 & 13,1 & 1,3 & 105,0 & 79,5 & 371,3 & 272,6 & 106,0 & - & - \\
\hline DLB & 7039 & 117,3 & 66,9 & 16,4 & 105,0 & 39,4 & 516,2 & 93,8 & 35,2 & - & - \\
\hline NPK & & & & & 105,0 & 60,0 & 70,0 & & & & \\
\hline
\end{tabular}

${ }^{1} \mathrm{MO}$ : matéria orgânica; ${ }^{2} \mathrm{TEST}$ : testemunha; ${ }^{3} \mathrm{DLS}$ : dejeto líquido de suínos; ${ }^{4} \mathrm{CSS}$ : cama sobreposta de suínos; ${ }^{5} \mathrm{DLB}$ : dejeto líquido de bovinos; ${ }^{6} \mathrm{NPK}$ : adubação mineral; ${ }^{7} \mathrm{MS}$ : matéria seca.

Fonte: Elaboração dos autores. 
Para o cálculo da quantidade de adubo a ser aplicada, tomou-se como base a análise de solo, realizada antes da semeadura do milho e da aplicação dos tratamentos de adubação, e as recomendações para a cultura do milho (CQFS, 2004), sendo a aplicação realizada a lanço, uma única vez, imediatamente antes da semeadura do milho. A quantidade aplicada dos adubos orgânicos baseouse no teor de N-total e no índice de eficiência de $\mathrm{N}$, enquanto as quantidades necessárias de $\mathrm{N}, \mathrm{P}$ e K na adubação mineral foram ajustadas utilizando-se ureia, superfosfato triplo (SFT) e cloreto de potássio $(\mathrm{KCl})$. O tratamento das sementes de milho com Trichoderma spp. foi feito com o produto comercial Agrotrich Plus ${ }^{\circledR}$, utilizando $1 \mathrm{~g}$ do produto/kg de sementes.

A semeadura do milho foi feita manualmente, no dia $01 / 11 / 10$, sendo utilizada a cultivar 30 F53 $\mathrm{Y}$, com seis linhas de semeadura de $5 \mathrm{~m}$ de comprimento e espaçamento de $0,45 \mathrm{~m}$ em cada subparcela, totalizando $12,5 \mathrm{~m}^{2}$, e população final de 78000 plantas $\mathrm{ha}^{-1}$. As sementes adquiridas apresentavam tratamento para controle de fungos de armazenamento com o produto Maxim ${ }^{\circledR}$ XL (ingrediente ativo: fludioxonil + metalaxyl-M), que na dosagem recomendada não apresenta efeito fungitóxico sobre Trichoderma spp. (RESENDE et al., 2004), não tendo sido tratadas por ocasião da semeadura. Durante todo o ciclo da cultura do milho, quando necessário, foi realizada a irrigação, por aspersão.

Foram avaliadas a produção de matéria seca de parte aérea, a incidência de podridões de colmo e a produtividade do milho e também foi realizada a identificação dos agentes causais das podridões de colmo. Com a finalidade de avaliar a produção de MS de parte aérea, três plantas de milho foram coletadas por subparcela, no estádio R1 (florescimento) (RITCHIE; HANWAY; BENSON, 1993), e secas em estufa ( $65^{\circ} \mathrm{C}$, até peso constante). $\mathrm{Na}$ avaliação da incidência de podridões de colmo, os colmos sintomáticos foram contados, em um total de 40 plantas, nas quatro linhas centrais de cada subparcela, no estádio R6 (maturação fisiológica), considerando plantas sintomáticas aquelas com descoloração do primeiro ou segundo entrenós e/ou aquelas com menor resistência à pressão dos dedos polegar e indicador (RIBEIRO et al., 2005). Os dados obtidos de incidência de podridões de colmo foram expressos em percentagem. Os $3 \mathrm{~m}$ centrais das linhas de cada subparcela foram colhidos, excetuando as bordaduras, sendo feito o cálculo da produtividade com os dados ajustados para a umidade de $13 \%$.

Os colmos sintomáticos foram coletados, lavados em água corrente, desinfestados com álcool $70 \%$ e hipoclorito de sódio $1 \%$ e acondicionados em caixas do tipo "gerbox", contendo papel filtro umedecido. Estas foram armazenadas em câmara de incubação $\left(25^{\circ} \mathrm{C}\right.$ e fotoperíodo de $\left.12 \mathrm{~h}\right)$ e os colmos avaliados quatro dias após. Os agentes causais das podridões de colmo foram identificados através da observação em microscópio estereoscópico e ótico e os fungos identificados conforme literatura (BARNETT; HUNTER, 1999).

Os dados foram checados quanto ao atendimento aos pressupostos matemáticos e submetidos à análise de variância e ao teste de Tukey, a 5\% de significância. Para os dados de produtividade foi utilizada a transformação $\log _{10}(\mathrm{x})$.

Não houve interação entre os fatores adubação e tratamento de sementes com Trichoderma spp. para a produção de matéria seca de milho, porém houve diferença significativa entre os níveis de ambos os fatores avaliados (Tabela 2). 
Tabela 2. Matéria seca, incidência de podridões de colmo e produtividade de milho em função da adubação orgânica e mineral e do tratamento das sementes com Trichoderma spp.

\begin{tabular}{|c|c|c|c|c|c|c|}
\hline \multirow{3}{*}{$\begin{array}{l}\text { Tratamento } \\
\text { DLS }^{1}\end{array}$} & \multicolumn{6}{|c|}{ Matéria seca $\left(\mathrm{kg} \mathrm{ha}^{-1}\right)$} \\
\hline & \multicolumn{2}{|c|}{ Sem Trichoderma spp. } & \multicolumn{2}{|c|}{ Com Trichoderma spp. } & \multicolumn{2}{|c|}{ Média } \\
\hline & 12447 & ns & 12630 & ns & 12538 & $\mathbf{a}^{*}$ \\
\hline $\mathrm{NPK}^{2}$ & 10721 & ns & 11108 & ns & 10914 & $\mathbf{a b}$ \\
\hline $\mathrm{CSS}^{3}$ & 10042 & ns & 10524 & ns & 10283 & $\mathbf{b}$ \\
\hline $\mathrm{DLB}^{4}$ & 10590 & ns & 9889 & ns & 10240 & b \\
\hline TEST $^{5}$ & 6959 & ns & 7516 & ns & 6988 & c \\
\hline Média & 10052 & B & 10333 & $\mathbf{A}$ & & \\
\hline \multirow{2}{*}{ Tratamento } & \multicolumn{6}{|c|}{ Incidência de podridões de colmo (\%) } \\
\hline & \multicolumn{2}{|c|}{ Sem Trichoderma spp. } & \multicolumn{2}{|c|}{ Com Trichoderma spp. } & \multicolumn{2}{|c|}{ Média } \\
\hline DLS & 26,9 & ns & 25,6 & ns & 26,3 & $a^{*}$ \\
\hline NPK & 25,0 & ns & 16,3 & ns & 20,6 & ab \\
\hline CSS & 16,9 & ns & 13,8 & ns & 15,3 & $\mathbf{a b}$ \\
\hline DLB & 11,3 & ns & 12,5 & ns & 11,9 & bc \\
\hline TEST & 3,1 & ns & 2,5 & ns & 2,8 & c \\
\hline Média & 16,6 & ns & 14,1 & ns & & \\
\hline \multirow{2}{*}{ Tratamento } & \multicolumn{6}{|c|}{ Produtividade (kg ha $\left.{ }^{-1}\right)$} \\
\hline & \multicolumn{2}{|c|}{ Sem Trichoderma spp. } & \multicolumn{2}{|c|}{ Com Trichoderma spp. } & \multicolumn{2}{|c|}{ Média } \\
\hline NPK & 9601 & ns & 9351 & ns & 9476 & $\mathbf{a}^{*}$ \\
\hline DLS & 8606 & ns & 7884 & ns & 8245 & b \\
\hline CSS & 7070 & ns & 7270 & ns & 7170 & c \\
\hline DLB & 6521 & ns & 7049 & ns & 6785 & c \\
\hline TEST & 4411 & ns & 3683 & ns & 4047 & d \\
\hline Média & 7242 & ns & 7047 & ns & & \\
\hline
\end{tabular}

${ }^{1}$ DLS: dejeto líquido de suínos; ${ }^{2} \mathrm{NPK}$ : adubação mineral; ${ }^{3} \mathrm{CSS}$ : cama sobreposta de suínos; ${ }^{4} \mathrm{DLB}$ : dejeto líquido de bovinos; ${ }^{5}$ TEST: testemunha.

"Médias seguidas por letras maiúsculas diferentes na linha e por letras minúsculas na coluna diferem entre si pelo teste de Tukey, a $5 \%$ de significância. ${ }^{\text {ns: }: ~ n a ̃ o ~ s i g n i f i c a t i v o . ~}$

Fonte: Elaboração dos autores.

Quando se avaliou o fator adubação, maior produção de MS foi obtida no tratamento DLS, que não diferiu do tratamento NPK, e todos os tratamentos tiveram produção superior ao tratamento testemunha. $\mathrm{O}$ incremento na produção de MS de parte aérea utilizando os tratamentos DLS, CSS, DLB e NPK foi de 79,4\%, 47,1\%, 46,5\% e 56,2\% em relação ao tratamento testemunha, respectivamente, demonstrando que bons resultados para a produção de MS podem ser obtidos não somente com a adubação mineral, mas também com a adubação orgânica e, nesse caso em particular, com o dejeto líquido de suínos, que proporcionou incremento maior que a adubação mineral. Ceretta et al. (2005) verificaram incremento na produção de MS com a utilização do DLS em aveia preta, milho e nabo forrageiro, em todas as doses utilizadas $(20,40$ e 80 $\mathrm{m}^{3} \mathrm{ha}^{-1}$ ), corroborando com os resultados obtidos no presente trabalho para a cultura do milho.

Para o fator tratamento de sementes, maior produção de MS foi obtida com Trichoderma spp., havendo incremento de $2,8 \%$ em relação ao tratamento sem Trichoderma spp. Outros autores encontraram resultados semelhantes, constatando maior produção de MS de raízes de milho em plantas oriundas de sementes tratadas comparativamente às não tratadas com T. harzianum (RESENDE et al., 2004). 
Quanto à incidência de podridões de colmo no milho, não houve interação entre os fatores adubos e tratamento das sementes (Tabela 2). Foi observada diferença apenas para os níveis do fator adubação, em que menor incidência de podridões de colmo foi verificada no tratamento testemunha, não diferindo estatisticamente do DLB, enquanto maior incidência foi observada no tratamento DLS, que não diferiu da CSS e do NPK.

Trichoderma spp. não reduziu a incidência de podridões de colmo no milho. É possível que as cepas utilizadas neste trabalho não tenham sido capazes de colonizar a rizosfera da planta e, portanto, não exerceram seu potencial anti-fitopatogênico, pois a maioria dos trabalhos existentes nessa área demonstra uma redução na incidência de doenças quando utilizado Trichoderma spp. em diversas culturas. Em tomateiro, por exemplo, o isolado T34 de $T$. asperellum protegeu as plantas da ocorrência da murcha de Fusarium através da competição por Ferro (Fe) (SEGARRA et al., 2010).

A interação entre os fatores, não observada no presente trabalho, em contrapartida, foi observada em estudos realizados por outros autores. Um exemplo disso é que a adição de biofertilizante, composto por aminoácidos, dejetos de suínos e Paenibacillus polymyxa, aumentou a eficácia de controle da murcha de Fusarium em melancia (LING et al., 2010). Porém, os trabalhos envolvem diferentes espécies de plantas, de micro-organismos e diferentes condições experimentais, o que justifica a diferença em relação aos resultados obtidos no presente estudo.

Quanto à identificação dos agentes causais das podridões de colmo no milho, observou-se a presença simultânea dos gêneros fúngicos Fusarium e Stenocarpella na maioria dos colmos avaliados. Ribeiro et al. (2005) também identificaram os fungos Fusarium spp. e Stenocarpella spp. em colmos de milho apresentando podridão, entretanto, o principal agente causal identificado foi o fungo
C. graminicola. A não ocorrência do fungo $C$. graminicola nos colmos de milho, no presente trabalho, pode ter sido devido à ausência do patógeno na área de cultivo ou maior resistência do genótipo ao fungo.

Para a variável produtividade de milho, não houve interação entre os fatores (Tabela 2) e não houve diferença entre os tratamentos com e sem Trichoderma spp., embora tenha sido observada maior produção de MS quando houve o tratamento das sementes com Trichoderma spp. Considerando somente o fator adubação, maior produtividade foi alcançada com a adubação mineral. Todos os tratamentos alcançaram produtividade significativamente superior ao tratamento testemunha, sendo observados incrementos de 68, 77, 104 e 134\% nos tratamentos DLB, CSS, DLS e NPK, respectivamente, em relação ao tratamento testemunha. Esses resultados se assemelham aos encontrados por Giacomini e Aita (2008), em que maior produtividade de milho foi obtida com adubação mineral e dejetos líquidos de suínos, em relação ao tratamento testemunha.

Conclui-se que os adubos orgânicos aumentam a produção de matéria seca de parte aérea e a produtividade de milho, porém provocam aumento na incidência de podridões de colmo, e Trichoderma spp. proporciona aumento na produção de matéria seca de parte aérea de milho, entretanto, não reduz a incidência de podridões de colmo.

\section{Apresentação e Agradecimentos}

Trabalho realizado como parte da dissertação de Mestrado do primeiro autor no Programa de PósGraduação em Agronomia da Universidade Federal de Santa Maria. Os autores agradecem a CAPES, FIPE/UFSM e CNPq pelo auxílio concedido. 


\section{Referências}

ALMEIDA, A. C. R. Uso associado de esterco líquido de suinos e plantas de cobertura de solo na cultura do milho. 2000. Dissertação (Mestrado em Agronomia) Universidade Federal de Santa Maria, Santa Maria.

BARNETT, H. L.; HUNTER, B. B. Ilustrated genera of imperfect fungi. 4. ed. Minnesota: American Phytopathology Society, 1999. 218 p.

BENÍTEZ, T.; RINCÓN, A. M.; LIMÓN, M. C.; CODÓN, A. C. Biocontrol mechanisms of Trichoderma strains. International Microbiology, v. 7, n. 4, p. 249260, 2004. Disponível em: <http://www.im.microbios. org/0704/0704249.pdf>. Acesso em: 16 abr. 2011.

CASELA, C. R.; FERREIRA, A. S.; PINTO, N. F. J. A. Doenças na cultura do milho. Sete Lagoas: [s.n.], 2006. 14 p. (Circular técnica, 83).

CERETTA, C. A.; BASSO, C. J.; PAVINATO, P. S.; TRENTIN, E. E.; GIROTTO, E. Produtividade de grãos de milho, produção de matéria seca e acúmulo de nitrogênio, fósforo e potássio na rotação aveia preta/ milho/nabo forrageiro com aplicação de dejeto líquido de suínos. Ciência Rural, Santa Maria, v. 35, n. 6, p. 1287-1295, nov./dez, 2005. Disponível em: <http://www. scielo.br/pdf/cr/v35n6/a10v35n6.pdf >. Acesso em: 18 abr. 2011.

COMISSÃO DE QUÍMICA E FERTILIDADE DO SOLO - CQFS - RS/SC. Manual de adubação e calagem para os Estados do Rio Grande do Sul e Santa Catarina. Porto Alegre, SBCS, 2004. 400 p.

COMPANHIA NACIONAL DE ABASTECIMENTO - CONAB. Acompanhamento da safra brasileira de grãos. Primeiro levantamento, 2010. Disponível em: $<$ http://www.conab.gov.br/OlalaCMS/uploads/arquivos/ fc9304890a88b451d5d992377687b0f9.pdf $>$.Acesso em: 20 dez. 2010.

EL-HASSAN, S. A.; GOWEN, S. R. Formulation and delivery of the bacterial antagonist Bacillus subtilis for management of lentil vascular wilt caused by Fusarium oxysporum f. sp. lentis. Phytopathology, v. 154, n. 3, p. 148-155, 2006. Disponível em: <http://onlinelibrary. wiley.com/doi/10.1111/j.1439-0434.2006.01075.x/ abstract $>$. Acesso em: 15 jun. 2011.

GHORBANI, R.; WILCOCKSON, S.; KOOCHEKI, A.; LEIFERT, C. Soil management for sustainable crop disease control: a review. Environmental Chemistry Letters, v. 6, n. 3, p. 149-162, 2008. Disponível em: <http:// www.springerlink.com/content/h4116580106w2673/>. Acesso em: 15 jun. 2011.

GIACOMINI, S. J.; AITA, C. Cama sobreposta e dejetos líquidos de suínos como fonte de nitrogênio ao milho.
Revista Brasileira de Ciência do Solo, Viçosa, MG, v. 32, n. 1, p. 195-205, 2008. Disponível em: <http://www. scielo.br/pdf/rbcs/v32n1/19.pdf>. Acesso em: 18 abr. 2011.

LING, N.; XUE, C.; HUANG, Q.; YANG, X.; XU, Y.; SHEN, Q. Development of a mode of application of bioorganic fertilizer for improving the biocontrol efficacy to Fusarium wilt. Biocontrol, v. 55, n. 5, p. 673-683, 2010. Disponível em: <http://www.springerlink.com/ content/pn6lu234094k2743/>. Acesso em: 12 mar. 2011.

PINTO, N. F. J. A.; OLIVEIRA, E.; FERNANDES, F. T. Manejo das principais doenças do milho. Sete Lagoas: [s.n.], 2007, 16 p. (Circular técnica, 92).

RESENDE, M. L.; OLIVEIRA, J. A.; GUIMARÃES, R. M.; VON PINHO, R. G.; VIEIRA, A. R. Inoculação de sementes de milho utilizando o Trichoderma harzianum como promotor de crescimento. Ciência e Agrotecnologia, Lavras, v. 28, n. 4, p. 793-798, jul./ago. 2004. Disponível em: $\quad<\mathrm{http}: / /$ www.scielo.br/scielo.php?script=sci arttext\&pid $=$ S1413-70542004000400010\&lng $=$ en $>$. Acesso em: 16 abr. 2010.

RIBEIRO, N. A.; CASA, R. T.; BOGO, A.; SANGOI, L.; MOREIRA, E. N.; WILLE, L. A. Incidência de podridões do colmo, grãos ardidos e produtividade de grãos de genótipos de milho em diferentes sistemas de manejo. Ciência Rural, Santa Maria, v. 35, n. 5, p. 1003-1009, set./ out. 2005. Disponível em: <http://www.scielo.br/scielo. php?pid=S0103-84782005000500004\&script $=$ sci_ abstract\&tlng=pt $>$. Acesso em: 12 set. 2010.

RITCHIE, S. W.; HANWAY, J. J.; BENSON, G. O. How a corn plant develops. Ames, Iowa: Iowa State University of Science and Technology, 1993. (Special Report, n. 48). Disponível em: <http://www.potafos.org/ppiweb/ brazil.nsf $/$ webindex/article $=$ A687D81283256DCD006 F37C8BC5FFFEF>. Acesso em: 31 maio 2010.

SEGARRA, G.; CASANOVA, E.; AVILÉS, M.; TRILLAS, I. Trichoderma asperellum strain T34 controls Fusarium wilt disease in tomato plants in soilless culture through competition for iron. Microbial Ecology, v. 59, n. 1, p. 141-149, 2010. Disponível em: <http://www. springerlink.com/content/d5581727x37h2202/>. Acesso em: 15 jun. 2011.

SULLIVAN, P. Sustainable management of soilborne plant diseases. ATTRA, USDA's rural business cooperative service. 2004. Disponível em: $<\mathrm{http}: / / \mathrm{www}$. attra.org/attra-pub/soilborne.html>. Acesso em: 15 jun. 2011.

TEDESCO, M. J.; GIANELlO, C.; BISSANI, C. A. Análise de solo, plantas e outros materiais. Porto Alegre: Departamento de Solos, UFRGS, 1995. 174 p. 
